\title{
From Experience to Summit or Vice Versa? Netnography Study on a Virtual Community of Mountaineering ${ }^{i}$
}

\author{
Sabri Kaya ${ }^{1, *}$, Metin Argan², Gözde Yetim² \\ ${ }^{1}$ Faculty of Sport Sciences, Kirikkale University, Turkey \\ ${ }^{2}$ Faculty of Sport Sciences, Anadolu University, Turkey
}

Copyright $(2017$ by authors, all rights reserved. Authors agree that this article remains permanently open access under the terms of the Creative Commons Attribution License 4.0 International License

\begin{abstract}
Virtual communities have been a significant channel for people to share their feelings and experiences regarding a special issue. The combination of ethnography and the internet offers the opportunity for new methods of research that can potentially reach a broad audience in the online world. Thus, netnography, a combination of internet and ethnography, is an approach to analyze the online community systematically. This study aimed to reveal the experiences and feelings of a virtual community comprised of mountaineers in a virtual community. This research uses Kozinet's netnography approach on experiences and feelings, applied to a virtual community context, in order to better understand the nature of the sharing of a serious leisure community. The results of this study indicated that three main themes and nine sub-themes portray experiences, feelings, perceptions and group interaction of the virtual mountaineering community. This study emphasizes the themes of adventure experiences, preparation and supply, and completion, taking into account mountaineers' feelings and experiences in the virtual community.
\end{abstract}

Keywords Virtual Communities, Online Communities, Mountaineering, Experiences

\section{Introduction}

The growth of the internet and interactive websites has led to the creation of online communities that serve as points of reference for word of mouth and, in particular, for independent, personal and experiential information. With the advances in the information and communication technologies, internet usage has increased and plenty of virtual communities have sprung up in many fields. The concept of community in virtual world has started to be considered as gatherings of individuals through non-face-to-face methods [9]. Although, until almost 15 years ago, the main aim was to build face-to-face communication among consumers through various ways, nowadays it is to analyze the online activities of people in order to understand them much better [35]. Along with the wide range of purposes including talking, receiving emotional support, sharing, gossiping, playing, flirting, rebuilding identities or just spending some time, the usage of computer-based communication constitutes a base for building a social world full of communities referred to as virtual, digital, electronic or online [51].

Due to the increase in the number of virtual communities, it has become easier to exchange information with people all around the world. Many people participate in virtual communities to acquire information or to solve their problems. Therefore, virtual communities depend mostly on the communication and interactions among users. By this means, the participants form new bonds and protect existing ones, as well as build social interaction in virtual communities [52]. Thanks to these communities, it is quite possible for individuals to communicate with others from all strata and to exchange ideas about the topics they are interested in smoothly and without any limitations of time, setting or status. In addition to the virtual communities of education, health and art, in the field of sports, especially adventure sports, users are able to share their own knowledge, experience, emotions and problems. These sharing activities could be both useful for those who are actively dealing with adventure sports, and instructive for others who are new to the field.

Virtual communities were created in order to share interests and information thanks to improvements in communication technology. This social and cultural phenomenon can be seen in the online sports communities, especially the sharing of information [50]. Thus, virtual sports discussion blogs have become popular. Sports-themed online communities have several advantages, such as acquiring a supportive and stable fan base, embracing the team and the sportsmen in the long term and having a radical structure. The uniqueness of virtual communities with sports content is determined by the features of the sports itself. Regarding the sports branch, especially football, Europe 
focuses mostly on social properties like national belonging, fan identity or community engagement [12]. Even though experiences and feelings in a special virtual community are considered an important variable in sport studies, rarely has it been related to leisure, especially in the mountaineering context, or to the consideration of different serious leisure experiences. Hence, the purpose of this paper is to investigate the themes or dimensions for mountaineers in a virtual special group, taking into account the shares of the virtual group's members. For this reason, this study focuses on mountaineering, which is an adventure sport, or serious leisure.

\section{Literature Review}

\subsection{Virtual Communities}

Virtual communities enable people to discuss some common topics such as their hobbies, health conditions, emotions and experiences in an internet environment. Virtual communities assemble people in order to let them gather information on collectively created topics [3]. Studies reveal plenty of descriptions regarding virtual communities. Jones and Rafaeli [19] and Lee et al. [24] explain virtual communities as computer-based areas where individuals make contact with each other in a relatively straightforward and transparent way by interacting or encouraging each other to communicate via the internet. According to Chen et al. [3], virtual communities are non-official communities where individuals sharing similar interests and experiences gather together without an official contract. Furthermore, Wenger [45] and Chen et al. [3] states that virtual communities allow people to talk about their experiences and ideas while concentrating on a specific topic by sharing and internalizing written information. Kozinets [21] indicates that the definition of a virtual community has three factors: 1 . Internet / cyber world symbolizes activities done in the cyber world as distinct from real communal activities; 2 . the exchange of ideas refers to sharing ideas and knowledge, experiences, emotions and interests in the topics created by the website users; 3 . personal relations could be defined as the relationship developed between the users.

Hagel and Armstrong [13] categorized virtual communities as having four basic needs: field of interest, mutual relations, fantasy and transaction. Field of interest refers to sharing information and experience on various topics. Mutual relations can be explained as communication between individuals who share similar experiences and opportunities. Fantasy can be depicted as individuals' discovery of a new world consisting of fantasy and entertainment and transaction can be described as information exchange performed by individuals with each other. Jones and Rafaeli[19] developed this classification and focused on social structure and technology as well (Lee et al. [24]. The concept of virtual communities was first put forward by Rheingold [34] cited in Chou and Sawang [4] as 'internet-based social gatherings where enough numbers of individuals with sufficient emotions communicate publicly for an appropriate period of time in order to develop personal relations in virtual areas'. A virtual community is a social combination of people's general values and fields of interests in the internet and computers [33, 52]. Balasubramanian and Mahajan [2] define the features of virtual communities as:

- Bringing people together

- Rational members

- Interaction in the cyber world without any physical contact

- Social change process

- Possessing features such as common purpose and interest of the members.

So far, there have been very few studies done on virtual communities interested in online sports organizations. The existing studies focus generally on runners. Eagleman and Hack [7], while analyzing the website "ning.com", found a positive correlation between the number and duration of visits to the site and participation in running competitions. When they examined the demographic features, they found that young participants were more active in virtual communities than older ones. Osti [29] indicated some basic features which make virtual communities important in activities such as mountaineering and traveling: bringing up new topics and creating an opportunity to browse, information reliability, contribution to the new topics by all the users, regionalistic and homogeneous structure, and the opportunity to form real communities as well as virtual ones.

\subsection{Netnography}

The internet is filled with information on every topic imaginable. It is an outlet for people to express their ideas, emotions and opinions about every topic. The last decade, researchers have been using this pool of data for a variety of research purposes by means of a methodology called netnography.

Briefly, it can be describe that netnography is the combination of 'internet' and 'ethnography'. Netnography is an ethnographic implementation in a computer-based environment, and is called digital or virtual ethnography. In line with qualitative research, netnography is essential to provide an opportunity to comprehend and to form an opinion about the relations between virtual environments and the symbolic meanings of consumers' needs, demands and choices [22]. Ethnography is an anthropological method which has become popular in the fields of sociology, cultural studies, consumer analysis and social sciences [22]. Traditionally, normative and qualitative approaches are developed by adopting qualitative and ethnographic methods which enlighten postmodern methods and are used in order to comprehend consumer experiences. These methods have started to be used in the online environment [48]. Robert Kozinets, a pioneer of netnography, first defined and used it 
in 1997. He defined netnography as "a written account of online cyberculture, informed by the methods of cultural anthropology" [53]. Netnography, or online ethnography, involves a researcher joining, recording, analyzing and interpreting the content of an online e-tribe or social media site. Thus, netnography, like ethnography [54] is about a researcher observing and recording, for an extended period of time, the acts and discussions of a target population.

Netnography is unsolicited, realistic and unobtrusive; it is less time consuming and expensive than ethnography [23]. It allows the researcher to gain deeper insights into consumers' opinions, motives, worries and concerns in an inconspicuous manner [55]. Observing the behavior of individuals online rather than face-to-face eliminates the human aspect of the observation. All of the data collected from an online forum is usually in a textual format, and, therefore, cannot include data that could be relevant to an ethnographer, such as body language, eye contact, tone of voice, posture, general mood and movements. However, it does follow the same epistemology as ethnography in that results are not generalized to broader contexts but simply represent a particular observation of a lived experience which can inform decisions or future research[23].

\subsection{Serious Leisure and Mountaineering}

Stebbins [37] has divided leisure time activities into the two groups of serious leisure and casual leisure. Serious leisure activities signify long-term participation in activities requiring special abilities, knowledge and experience. This would include the activities of those who are loyal to their hobbies as well as specialized social volunteers [38,30]. Casual leisure, on the other hand, refers to daily activities such as watching $\mathrm{TV}$, reading a book, listening to music etc. in which there is no need for continuity, making much effort or developing a skill [16].

When the difference between serious leisure and casual leisure was studied, it was observed that the individuals in serious leisure participate in the activities more regularly and consistently in order to develop their knowledge, skills and abilities, whereas those in casual leisure participate intermittently in the activities just for fun and without planning any career in that field [1]. In this respect, mountaineering can be evaluated within the scope of serious leisure, since individuals take part in this activity regularly and consistently, and they are professionally improving themselves along with their knowledge and skills as a result of long-term efforts and work. For this reason, there are some distinctive characteristics of the participants of serious leisure in comparison with those of casual leisure [11, 27].

When these distinctive features are studied in the perspective of mountaineering which is evaluated as a serious leisure activity:

- Mountaineers show determination and continue the climbing activity until the end even if they encounter a number of difficulties.
- Mountaineers are provided with professional development as a result of a long-term effort consisting of possibilities, peak points and accomplishments.

- Mountaineers spend individual effort in climbing activities requiring knowledge and skills, and take pains with it for a long time, often with professional help.

- Mountaineers, from their participation in climbing activities, gain long-term benefits such as self-esteem, self-actualization and social interactions.

- Mountaineers form social organizations with those who share the same interests and in this organization there is a unique environment replete with the norms, values, behavior and the language of the individuals.

- Mountaineers obtain a social identity based on the sense of belonging they develop through climbing activities.

Those analyzed in this study can be divided into amateurs, hobbyists and the volunteers who are the participants of serious leisure activities [36]. Amateurs participate regularly in various activities for a long time and in a disciplined way, and they become a part of the professional-amateur-public system. In this respect, it could be said that amateurism is a precursor to professionalism. As another type of participant of serious leisure, hobbyists fall into the four categories of collectors, manufacturers and repairers, participants of activity and participants of sports and games, and they spend effort only in order to get professional expertise rather than doing a short-term activity.

In this context, each of the individuals who adopt mountaineering as a hobby, i.e. individuals who spend much time and effort in order to improve themselves professionally and to acquire self-realization, could be regarded as the participants of an activity. On the other hand, volunteers who participate in serious leisure act together with the group in order to help others voluntarily, without the purpose of making profit and without any constraint or pressure. People interested in mountaineering in the context of volunteerism help each other by joining various virtual communities and by sharing their opinions and experiences without any purpose of making a profit or earning money.

According to the definition made by Stebbins $[36,37,38]$, individuals participate in serious leisure in order to contribute to their professional development, to achieve a career, to get a concrete and continuous benefit as well as to just do physical activities in many branches of sport. Additionally, in his study, Peng [31] analyzed the life of Nelson Yang and searched for his commitment to the academic research related to mountaineering. The interesting point in that study is that Nelson has spent more time and energy in mountaineering as a hobby and in related academic research than he does in his full-time job. Yang's devotion to mountaineering is emblematic of the "serious leisure careers" of Stebbins.

\subsection{Mountaineering Flow Experience}

Flow experience is a dominant phenomenon in 
mountaineering, as well as in many other sport experiences. The concept of flow was put forward by Csikszentmihalyi in 1975 [5]. Flow is considered as an intense interest, deep concentration and enthusiasm about an activity $[5,14,39]$. The flow experience as a physical activity plays an important role in developing self-respect and courage in the future participants $[6,18]$. The flow generally occurs during certain physical activities such as running, long distance walk and mountaineering. High-risk adventure sports like mountaineering provide perfect conditions for flow experience [46]. Webster et al. [44] have indicated that flow experience consists of the four dimensions of control, attention, curiosity and interest in the activity. Flow experience occurs as an enjoyable situation when the individual is strongly concentrated on the activity. In this matter, the participants are focused on experiencing the whole adventure rather than merely reaching the end. Regarding the flow experience, the balance between individuals' skills and the perceived difficulty level is an important factor. When those match, the flow occurs; however, when they do not, indifference or boredom shows up [46]. Csikszentmihalyi [5] defines flow as the state occurring when skill level and difficulty level are on a par. Jackson and Marsh [17] consider flow as an optimal balance between positive experiences and the ability of the person (cited in Tsaur et al., [40]). Nevertheless, Engeser and Rheinberg [8] claim that even if there is no balance between the difficulty level of the activity and the ability of the participant, the flow might occur anyway. They are of the opinion that the flow experience depends on how important the activity is to the person. Massimi and Carli [26] developed a model where they could explain four stages of flow: (1) flow occurs when the difficulty and skill levels required are above the competence of the person; (2) worry occurs when the difficulty level is above the competence and below the skill required, (3) boredom shows itself when the required skill is above the competence of the person, but below the difficulty level of the activity, and (4) indifference occurs if the required skills and difficulty are below personal competence.

\section{Methods}

The paper outlines and then implements the research methodology of netnography to achieve its purpose. This paper represents an empirical study that employs netnography to learn and investigate more about the feelings and mountaineering experiences among members of a virtual community. A netnography of a large online forum was carried out in order to respond to the research questions. Because of given the large number of online public forums available to internet users, the researchers conducted internet key word searches to narrow the options to forums that fit within the research parameters.

On the other hand ethnography is an anthropological method which has become popular in the fields of sociology, cultural studies, consumer analysis and social sciences [22]. Traditionally, normative and qualitative approaches are developed by adopting qualitative and ethnographic methods which enlighten postmodern methods and are used in order to comprehend consumer experiences. These methods have started to be used in the online environment [48].

Since netnography is an open-ended implementation of ethnography applied online, it guides the researcher in all the stages of the study [22, 23]. Kozinets [22] indicated that a netnographic approach includes the following stages: (1) blending in the community to be researched, (2) data collection and data analysis, (3) providing reliability, (4) implementing an ethical research and (5) providing opportunities for the members to give feedback. Additionally, Kozinets [22] proposes the following steps with regard to the implementation of netnography procedures" Entree: the identification the research questions and specific virtual community, especially through search engines. Data collection and analysis: Copying of data on virtual communities and in-depth examination of observations, interactions, and meanings about virtual community members. Trustworthy interpretation: to focus on "trustworthiness" rather than on "validity," and focus on procedures of classification, coding, reporting and triangulation. Research ethics: (1) Researchers should explain their presence to online community members during any research; (2) the researchers should ensure confidentiality and anonymity to informants; (3) the researcher should seek and incorporate feedback from members of the online community being researched; (4) The researcher should take a cautious position on the private-versus-public medium issue. Member checks: presenting some or all of a final research report's findings to the members who have been studied in order to solicit their comments. This research is based on the execution of the steps of the netnography method.

In order to have in-depth knowledge about mountaineers' experiences in a virtual community, netnography was used for data analysis and interpretation. In this study adopts a netnography study approach for investigating and analyzing how members (mountaineers) express their feelings on experiences on www.gezenbilir.com. According to Hartley [15] a single case study is suited to research that "explores new and emerging process of behavior" and allows researchers greater opportunity to explore a subject in more depth [20]. The online mountaineering platform in Turkey investigated for this netnography study was selected based on the criteria of having public online community and having open membership system. Individual who have an interest in mountaineering access the related web site to see posts made by peers or others. This web site is a virtual community developed by people with the similar serious leisure hobby. The members on this community discuss various issues and mountaineering-oriented ideas, share their experiences and make social interaction. The period of the study was from 
August 2015 to October 2015. Due to the large amount of information on the website, only the most widely read forums were analyzed. Therefore, the final sample contained only climbing reports with 965 issues and 9.358 responses. Data collection and analysis followed the established and strict netnographic research protocols developed by Kozinet [22].

\section{Findings}

This netnographic study evaluates the climbing reports written by professional climbers who are members of the Gezenbilir.com website. The mountaineering experiences of this virtual community have been divided into three main and nine sub-categories following the content analysis of the sport. The three main categories are 'Preparation and Supply', 'Adventure' and 'Completion' and the nine sub-categories are 'essential requirements', 'equipment', 'climbing costs', 'weather conditions', 'problems and dangers', 'acclimatization', 'hedonism', and 'satisfaction' and 'happiness'.

\subsection{Preparation and Supply}

As mentioned in the climbing reports, during the stages of preparation and supply, the climbers get the necessary equipment and route information after they choose a spot to visit. Moreover, there is detailed information given in the reports regarding the arrival at the spot (vehicle, cost, duration, and contact info.) and meeting with the participants coming from different cities. Consult the local gendarmerie and providing them with the personal and route information of the climbers is emphasized. In addition, the spot to start climbing, altitude, detailed route line, target duration and total costs play an important role in the preparation stage. As an example;

"After taking in some carbohydrates, we organized detailed information in order to answer all the possible questions the participants might have had in their mind."

\subsubsection{Essential Requirements}

In activities like mountaineering; food, accommodation (tent, sleeping bag, mountain house, hotel etc.) and toilet are some of the basic needs. Therefore, it is essential to prepare a sufficient amount of equipment appropriate for the environment. Just as in the needs hierarchy of Maslow [25], basic needs like food and accommodation are on the top in mountaineering as well. It is not possible to go on climbing without making necessary preparations. Hence, meeting the essential requirements and needs is crucial for the sake of climbing. There are some instances mentioned in the reports:

"We are enjoying our last night in meteo after compensating some of our carbohydrate loss."
"Since I did not have any appropriate clothing, my arms got almost frozen. That is why I chose to go back after 4800 $m t$, to avoid taking more risks."

\subsubsection{Equipment}

Equipment forms an important part of mountaineering. It is essential to choose appropriate equipment for the features of the climbing area. Equipment can be divided into the two categories of personal and technical equipment. Technical equipment includes ice screw, security belt, helmet, rope, pickaxes, spiky boots, walking stick etc.

Personal equipment includes water/wind proof clothes for the weather, appropriate shoes, backpack, flask, lantern, furnace, sun lotion, medicine, camera, flag (for the summit) etc. As the usage of the equipment might change depending on the area, it is crucial to choose the right one to use.

"Since the ground was full of swampy snow after $2500 \mathrm{mt}$, we decided to put on our spiky boots. Even with them, it was still very hard to walk on the snow."

"There was a surprise waiting for us when we reached the valley: ice. Even though we expected to see some snow as we did in the previous years, we found ice. After putting on spiky boots, we did not need to use the rope on the ice even though we had he necessary equipment."

\subsubsection{Climbing Cost}

During the activity, there are some costs to be covered. There is detailed information about the costs in the climbing reports, which makes future climbing easier at the same spot. The reports mention per person costs of transportation, food, accommodation, acquisition of necessary equipment and guidance etc.

\subsubsection{Guidance Service}

It is essential to state that a guide should have the technical knowledge of the route and mountaineering, and he should carry the qualifications of a good leader to be able to manage a group of people. Here is a good example of guidance;

"We were climbing up on the stair-like path in the dark as if we were going up a skyscraper. When we held our heads up, we could see the Germans as though they were floating above us and we were passing them one by one. Because local guides had no technical knowledge, everyone was trying to take care of themselves."

\subsubsection{Transportation}

It includes the costs of the arrival to the area, chosen for climbing, by train, bus or plane; from the main area, reaching the climbing point by taxi, minibus or a private vehicle and transportation between camps in order to carry equipment.

"We started to negotiate to avoid paying $\$ 50$, which was the climbing fee. We tried all the possible ways not to pay it 
for 1-1,5 hours, but we failed. And in the end, after paying 71.000 IRR per person, we got our climbing permits."

\subsection{Adventure}

As stated in the activity reports of climbers, summit climbing is the most emotional and the biggest event. Summit climbing is followed by writing in a memory notebook and photo shooting. In addition, occasionally, climbers choose to attend another summit activity called solo climbing, which is performed without camping;

"A couple of meters before the summit, our guides stopped and moved away saying 'Here you are; the summit is yours.' It was such a nice gesture that I got very emotional. I think I will always remember how I felt there. Because we were moving in slow motion, everything occurred slowly. The slope got lower. I took a few more steps. It was eight in the morning. The sun-rays suddenly started to hit my eyes from the shiny crystals on the floor. I was on the top of A $\breve{g r i}$ (Ararat) Mountain. My emotions got so intense that I could not hold my tears. We hugged and congratulated each other. We were at $5165 \mathrm{mt}$."

"We reached the summit by digging up a trail up and down while experiencing snow, fog, and storm."

\subsubsection{Weather Conditions}

Depending on the season, some activities were completed while exposed to rain, sun, fog, drizzle and storm. Besides, there are some cases in which the activities could not be completed due to adverse weather conditions. Weather conditions are quite important, especially while climbing up. Here are some useful examples explaining the effect of weather on climbing:

"We could take maximum two-three photos at the summit because of the heavy storm which was shooting ice particles like a bullet; we went down to the valley quickly and started our return journey after taking in some liquids."

"We ran into several teams who failed in reaching the summit because of the heavy weather condition even though the season was summer."

"Because of the slope and the strong wind, the snow was hitting our faces. It was very difficult to breathe oxygen, whose level was already low, when we covered our faces."

"The wind was shooting snow particles from the ground to our faces. We could not even hold our heads up to see the summit."

\subsubsection{Problems and Dangers}

In order to experience a relatively easier journey, it is essential to have knowledge about the potential and possible dangers during climbing. There is plenty of detailed information on the website regarding possible dangers that was analyzed in the research. In the reports, the common problems run into are exhaustion, toilet, lack of oxygen at $4000 \mathrm{mt}$ and above, high-altitude adaptation and weather conditions. Some are;

"Exhaustion was one of many problems. Air is thin, oxygen is low; you get tired very easily after taking a couple of steps. I told Attila about how I was feeling. He said I was moving as if I was down there on a street. I was supposed to move slower. So, I did. We started to move slower, like the astronauts on the moon. It really worked."

"At $4700 \mathrm{mt}$, we started to feel the effect of our fast movements and quick climbing that high within 14 hours. Nobody wanted to move, eat or drink anymore. However, we knew that we needed to go down as soon as possible. We were experiencing acclimatization problem and having terrible headaches, dizziness and exhaustion. Therefore, we started to return without losing any more time."

"The most difficult part of our activity was to open up trails in deep and soft snow. We took turns in every 50-60 steps. Despite this, it was quite hard to climb Küçükçal hill and we lost a lot of time."

Along with all these problems, falling rocks and health hazard situations due to adaptation failure are the main dangers people might encounter. To give examples of some dangerous experiences:

"Before getting to the moraines, we are taking off our boots while watching the falling rocks. Without losing anytime here, we are heading for the black cross quickly and carefully. Those falling rocks are quite dangerous and astonishing at the same time."

"Before sleeping, we do not forget to take precautions against any wild animal attack."

"My brother told me that he could not breathe and that his lungs were in pain. Without even thinking about Samistal, Hazindağ and Pokut Mountains, we went to Ayder and reached Pazar. While losing altitude, my brother was feeling worse and I was going mad. We took a cab and went to Kaçkar Hospital. The doctor gave him oxygen as the first thing. Afterwards, my brother started to feel much better. I was quite relieved. He ended up catching cold. He is very healthy now. He is a nature lover at the age of 17. He says he would go there again at any cost."

\subsubsection{Acclimatization (High-Altitude Adaptation)}

Acclimatization is the adaptation to high altitude. Due to the decreasing level of gas pressure while climbing, hypoxia may appear. The physiological and pathological reactions of the human body to various altitudes might change depending on each person. That is why it is essential to become familiar with the physiological and pathological changes occurring with the altitude [49]. Thus, while acclimatization becomes important on the way to the summit, it is crucial to have enough knowledge to interfere 
in case of acclimatization failure. It is quite common to run into similar situations in the activity reports. In order to get used to high altitudes, there are several practices performed such as climbing up and down, camping at a high spot and losing altitude in case of an adaptation failure. Here are some examples of the situation mentioned above:

"At 16.00, we climbed $300 \mathrm{mt}$ more with the decision of our team leaders in order to adapt to high altitude and waited there for a while. Around 18.00, we went back to our camp at $4200 \mathrm{mt}$."

"After preparing our bodies by climbing Aladağlar and Erciyes 2 weeks before our main climbing activity, we were finally on the way to Caucasia..."

"At 7.18 a.m. we found ourselves at the summit with our tired bodies out of the lack of oxygen and high altitude. We completed our adventure with the team of 8 . We performed a minute of silence for Ataturk; afterwards, we sang our national anthem. It was quite hard to stay sill because of the strong wind. We started to return as soon as we were done with photographing the view. We got pretty exhausted on the way back, one of the reasons of which might be due to acclimatization failure, which made me have a horrible headache and prostration."

"After setting up the tents and putting away our equipment, for the purpose of acclimatization, we walked until Deniz Lake."

\subsubsection{Hedonism}

Hedonism, in other words, is to enjoy satisfaction. Satisfaction is related to the empirical joy that an individual has experienced $[28,33]$. According to the climbing reports, the joy the climbers feel in mountaineering is the empirical joy they experience from the preparation to the completion. Therefore, hedonism plays a crucial role in choosing this sport and participating in it repeatedly. Accordingly, here are some examples of the satisfaction of the climbers:

"Apart from all the dangers, it is priceless to achieve something unique on your own."

"The main camp that we reached had actually been a Soviet shelter where fuel tanks had been in use. We had seen some photos before; however, it was quite different to witness it all firsthand. The view was amazing. On one hand, the majestic Elbrus with double summits was before us; on the other hand, the Caucasian Mountains were ahead of us."

"We started to feel the exhaustion resulting from the altitude. However, with the news coming from the leaders that we had only 20 min till the summit, we felt rejuvenated and started to climb up again. In about $15 \mathrm{~min}$, the view of the summit made us forget how tired we were. Thanks to the excitement of seeing the summit, we continued our journey, ignoring our exhaustion. When we got closer, we waited for other climbers and with tears of joy, we reached the summit, the dome of Europe, which we had been dreaming about for months and been curious about for four days. We enjoyed the view of Caucasia as much as we wanted, congratulated each other and started to climb down after taking some photos,

"I took a look from the tent and realized that a huge mass was watching us next to the majestic Mezovit Hill. The stars were amazingly pretty and the sky was full of them. If felt as if Mezovit Hill was guarding us with its black, shapeless silhouette. I acted as if I did not want to disturb the hill. I felt the need to take some pictures, so I ran to fetch my tripod."

"After an enjoyable 3-hour-climb, we have reached the Gusvensera Mountain House (3040 mt.), which looks like a mosque. The golden dome of the house is quite shiny. As soon as we entered inside, we started to melt some snow on the cartridge and gasoline furnace. Hot liquids, soups, pasta..."

\subsection{Completion}

While approaching the end of the adventure, the climbers go for their return journey full of satisfaction acquired from achieving their goal. The return journey is easier and takes less time compared to climbing up the slope. The climbers reach the camping area in a short time, prepare the equipment and continue their return. On their way, they plan another quest to be achieved.

\subsubsection{Satisfaction}

Mountaineering creates strong emotional experiences. These consist of various emotions such as joy, excitement, and fear. These emotions play a significant role in being satisfied by a mountaineering experience[10]. All the participants stated their feelings of joy, worry, excitement and satisfaction at having arrived at the summit with emotional words. Here are some statements of theirs:

"Finally, we started to feel the air we were looking for. We could smell sulphuric acid everywhere. At the summit, the wind was much stronger. Strong wind was on one side and the sulphuric acid was on the other. And eventually we were on the top of Demavend Mountain $(5671 \mathrm{~m})$. "'

"After 16-hour climbing, we were at the summit of A $\breve{g r l}$ (Ararat) and we wanted to enjoy it. That's why we spent one hour there."

"We are climbing the sharpest slope and we see the typical crater. At that point, we literally find ourselves on the clouds. With an amazing view, we are climbing the last meters to the summit. I find myself at the summit at 12 o'clock. After congratulating the others, I find a little rock cave under the sunshine away from the wind. We are waiting for the others to reach us while enjoying the view.",

\subsubsection{Happiness}

Happiness is defined as a form of experiences occurring 
as a result of hedonic satisfaction during an activity [40]. Happiness results mainly from what mountaineers experienced during the whole stages of climbing, rather than only reaching the summit. To give some examples of the happiness they experienced on the way to the summit given in the reports:

"The weather is quite nice and shiny. There is a little wind in the valley. The snow is amazing and climbing is enjoyable. We are climbing up while enjoying the weather."

"An incredible happiness is everywhere on the summit, everyone congratulates each other and we are very proud of ourselves. The only downside is the fog which makes it hard to see the view."

\section{Result and Discussion}

The main purpose of this study is to analyze the experiences of the sportsmen who performed mountaineering using an ethnographic approach. The findings of the netnography research point out three main themes and nine sub-themes. The first main theme is preparation and procurement, which refers to getting ready for the climb by acquiring the necessary equipment, route information etc. This theme consists of three sub-categories itself, which are the essential requirements, equipment and the climbing costs. At the stage of preparation and procurement, climbers become beneficial to other individuals who are interested in mountaineering, via spreading their experiences on an online platform. Therefore, those who intend to participate in climbing will be prepared and will be aware of the requirements, transportation, food costs etc. so that they will not experience problems in the beginning. In his study of Italian mountaineering virtual communities, Osti [29] stated that, like other mountaineering communities, this virtual community is a useful way of acquiring references about the activities such as potential trips and destinations. With the aid of electronic communication, members of the mountaineering virtual communities can obtain wider information about the sport.

The other main theme is adventure, which refers to the whole period from the start until the end of climbing. This theme includes four sub-categories which are weather conditions, problems and dangers, acclimatization (high-altitude adaptation) and hedonism. The satisfaction acquired from all these convince the individuals who have engaged in climbing activities to participate repeatedly. Similarly, studies show that by developing their skills and having them look for new challenges, flow experience and recreational expertise make people participate once more in special recreation activities [46]. As in the flow experience, in this activity, the climbers are motivated to experience all the stages of climbing, instead of focusing only on reaching the summit or the climbing performance [40].
Completion, which is the last main theme, symbolizes the intensity of the emotions of the climbers when they complete their journey to the summit. In the last stage of climbing, in addition to reaching the target, the climbers begin to go back with the satisfaction and happiness coming from the completion of previous stages. Adventure recreationists are likely to have flow experience which gives an intense feeling of happiness since the flow experience includes motivation towards an activity, focus and struggle and brings out the feeling of happiness [40]. The happiness of completing the climbing adventure leads to new adventures. Completion is divided into two categories; satisfaction and happiness. This study clearly supports previous researches. Walker et al. [42] stated that recreational outdoor activities increase the feeling of happiness and positive emotions are raised by the flow experience. Warburton and Veenhoven [43, 41] pointed out that satisfaction and happiness have a positive effect on health, as well. Tsaur et al. [40] indicated that happiness is a result of cognitive and emotional evaluations of the flow experience. Moreover, in their study on tourists interested in rafting, Wu and Liang [47] asserted that rafting skills of the tourists and the difficulty of rafting influence the flow experience positively and increase the mood and satisfaction. Overall, preparation and procurement phase is the most essential step for climbers. These results contribute conceptually to future research and the literature related to mountaineering experiences and climbers. In terms of clarifying and providing virtual mountaineering community experiences could be successfully linked and transferred by enhancing participation of other climbers.

\section{Limitation and Future Study}

Like all scientific research, especially qualitative research, this research, as well, carries certain limitations regarding its conduct. The most important limitation was that the study analyses only one virtual community. Additionally, the data were collected over a limited time period. Through analyzing more virtual communities interested in mountaineering, it will be possible in the future to reach more information about the mountaineering clubs/virtual communities belonging to different cultures. Furthermore, this netnography data was descriptive and exploratory, and not designed for quantitative hypothesis testing. Future studies may look at the different specific mountaineering groups. Additionally, future studies should expand the different communities and different regions. This research provides impetus for future work in the content area and in the use of the netnography method. And also this paper is original in a respect: the use of netnography as the research method in this context.

\section{Acknowledgements}

I would like to thank Mrs. Monica Woods from Foreign 
Languages Department at Bilkent College for her assistance with proofreading in this study.

\section{REFERENCES}

[1] Akyildiz M.M. \& Argan, M. (2016). Development of the Serious and Casual Leisure Measure. World Leisure Journal, 58 (2): $124-141$

[2] Balasubramanian, S. \& Mahajan, V. (2001). The Economic Leverage of the Virtual Community. International Journal of Electronic Commerce, 5 (3): 103-138.

[3] Chen, C.S., Chang, S.F. \& Liu, C.H. (2012). Understanding Knowledge-Sharing Motivation, Incentive Mechanisms, and Satisfaction in Virtual Communities. Social Behavior and Personality, 40 (4): 639-648.

[4] Chou, C.Y. \& Sawang, S. (2015). Virtual Community, Purchasing Behavior, and Emotional Well-Being. Australasian Marketing Journal, 23 (3), 207-217.

[5] Csikszentmihalyi, M. (1975). Beyond Boredom and Anxiety. San Francisco: Jossey-Bass.

[6] Csikszentmihalyi, M. (2000). Beyond Boredom and Anxiety. Experiencing Flow in Work and Play, 25th Anniversary Edition (Original: Beyond Boredom and Anxiety, 1975). San Francisco: Jossey-Bass Publishers.

[7] Eagleman, A.N. \& Hack, T. (2011). Road Race Series Participants' Event and New Media Preferences: A Case Study. Journal of Contemporary Athletics, 5 (4): 261-272.

[8] Engeser, S. \& Rheinberg, F. (2008). Flow, Performance and Moderators of Challenge-Skill Balance. Motiv. Emot. 32 (3): 158-172.

[9] Faria, W.L. \& Elliot, S. (2012). Understanding the Role of Social Media in Destination Marketing. Tourismos: An International Multidisciplinary Journal of Tourism, 7 (1): 193-211.

[10] Faullant, R., Matzler, K. \& Mooradian, T.A. (2011). Personality, Basic Emotions, and Satisfaction: Primary Emotions in the Mountaineering Experience. Tourism Management, 32 (6): 1423-1430.

[11] Green, B.C. \& Jones, I. (2005). Serious Leisure, Social Identity and Sport Tourism. Sport in Society, 8 (2):164-181.

[12] Gonzalez, H.L., Sole, F.G. \& Larrea, O. (2014). Community Building in the Digital Age: Dynamics of Online Sports Discussion. Communication \& Society, 27 (3): 83-105.

[13] Hagel, III, J. \& Armstrong, A.G. (1997). Net Gain: Expanding Markets Through Virtual Communities. Boston, MA: Harvard Business School Press.

[14] Han, S. (1988). The Relationship Between Life Satisfaction and Flow in Elderly Korean Immigrants. In Csikszentmihalyi, M., \& Csikszentmihalyi, I. (Eds.), Optimal experience: Psychological studies of flow in consciousness (pp. 138-149). New York: Cambridge.

[15] Hartley, J. (2004). Case study research in Cassell, C. \& Symon, G. (Eds), Essential Guide to Qualitative Methods in Organizational Research, Sage, London, pp.323-333.
[16] Hutzler, Y., Barda, R., Mintz, A. \&Hayosh, T. (2016). "Reverse Integration in Wheelchair Basketball: A Serious Leisure Perspective". Journal of Sport and Social Issues, 40 (4): 338-360.

[17] Jackson S.A. \& Marsh, H.W. (1996). Development and Validation of a Scale to Measure Optimal Experience: The Flow State Scale. Journal of Sport\& Exercise Psychology, 18 (1): 17-35.

[18] Janzik, L. \& Raasch, C. (2011). Online Communities in Mature Markets: Why Join, Why Innovate, Why Share? International Journal of Innovation Management, 15 (4): 797-836.

[19] Jones, Q. \& Rafaeli, S. (2000). "Time to Split, Virtually: Discourse Architecture' and 'Community Building Create Vibrant Virtual Publics. Electronic Markets, 10 (4): 214-223.

[20] Keeling, D., Khan, A. \& Newholm, T. (2013). Internet Forums and Negotiation of Healthcare Knowledge Cultures. Journal of Service Marketing, 27(1): 59-75.

[21] Kozinets, R.V. (1999). E-Tribalized Marketing? The Strategic Implications of Virtual Communities of Consumption. Journal of Advertising Research, 46 (3): 279-288.

[22] Kozinets, R.V. (2002). The Field Behind the Screen: Using Netnography for Marketing Research in Online Communities. Journal of Marketing Research, 39, 61-72.

[23] Kozinets, R.V. (2006). Click to Connect: Netnography and Tribal Advertising. Journal of Advertising Research, 46 (3): 279-288.

[24] Lee, F.S.L., Vogel, D. \& Limayem, M. (2003). Virtual Community Informatics: A Review and Research Agenda. Journal of Information Technology Theory and Application, 5 (1): 47-61.

[25] Maslow, A.H. (1954). Motivation and Personality. Harper \& Row, New York.

[26] Massimini, F. \& Carli, M. (1988). The Systematic Assessment of Flow in Daily Experience. In M. Csikszentmihalyi \& I. Csikszentmihalyi (Eds.), Optimal experience: Psychological studies of flow in consciousness (pp. 266-287). Cambridge University Press.

[27] Moularde, J. \& Weaver, A. (2016). Serious About Leisure, Serious About Destinations: Mountain Bikers and Destination Attractiveness. Journal of Sport \& Tourism, 20 (3-4): 285-303.

[28] Okada, E.M. (2005). Justification Effects on Consumer Choice of Hedonic and Utilitarian Goods. Journal of Marketing Research, 42 (1): 43-53.

[29] Osti, L. (2009). Creating UGC Areas on Official Destination Websites: Is There a Recipe for Success? An Insight Through Netnographic Research. An Int. Multidisciplinary J. of Tourism, 4 (3): 99-112.

[30] Park, K.W., Lee, C.W. \& Kim, M.J. (2016). Effect of Serious Leisure Experience on the Leisure Satisfaction among Senior Sport Games Participants. J. of Physical Education and Sport, 16 (1): 584-591.

[31] Peng, H.C. (2013). The Life and Adventures of Nelson Young: A Serious Leisure Approach to His Mountaineering and Academic Research. Networked Digital Library of Theses \& Dissertations. 
[32] Preece, J. (2001). On-line Communities: Designing Usability, Supporting Sociability. New York, NY: Wiley.

[33] Richard, M. O., \& Habibi, M. R. (2016). Advanced Modeling of Online Consumer Behavior: The Moderating Roles of Hedonism and Culture. Journal of Business Research, 69 (3): 1103-1119.

[34] Rheingold, H. (1993). The Virtual Community: Homesteading on the Electronic Frontier. Addison-Wesley, Reading, MA.

[35] Rocca, A.L., Mandelli, A. \& Snehota, I. (2014). Netnography Approach as a Tool for Marketing Research: The Case of Dash-P\&G/TTV. Management Decision, 52 (4): 689-704.

[36] Stebbins, R.A. (1982). Serious Leisure: A Conceptual Statement. The Pacific Sociological Review, 25 (2): 251-272.

[37] Stebbins, R.A. (1992). Amateurs, Professionals, and Serious Leisure. Montreal, Canada: McGill-Queen's University Press.

[38] Stebbins, R.A. (2007). Serious Leisure: A Perspective for Our Time. New Brunswick, NJ: Transaction.

[39] Tsaur, S.H., Lin, W.R. \& Cheng, T.M. (2015). Toward a Structural Model of Challenge Experience in Adventure Recreation. Journal of Leisure Research, 47 (3): 322-336.

[40] Tsaur, S.H., Yen, C.H. \& Hsiao, S.L. (2013). Transcendent Experience, Flow and Happiness for Mountain Climbers. International Journal of Tourism Research, 15 (4): 360-374.

[41] Veenhoven, R. (2003). Hedonism and Happiness. Journal of Happiness Studies, 4 (4): 437-457.

[42] Walker, G.J., Hull, R.B. \& Roggenguck, J.W. (1998). On-Site Optimal Experience and Their Relationship to Off-Site Benefits. Journal of Leisure Research, 30 (4): 453-471.

[43] Warburton, D.M. (1996). The Functions of Pleasure, in D.M. Warburton and N. Sherwood (Eds), Pleasure and Quality of Life (Wiley, Chichester).

[44] Webster J., Trevino L.K. \& Ryan L. (1993). The Dimensionality and Correlates of Flow in Human Computer Interactions. Computers in Human Behavior, 9 (4): 411- 426.

[45] Wenger, E. (1998). Communities of Practice: Learning, Meaning, and Identity. New York: Cambridge University Press.

\footnotetext{
i This paper has been presented at the Second International Conference on Tourism and Leisure Studies, held in University of British Columbia, Vancouver, Canada, April 6-7, 2017
}

[46] Wöran, B. \& Arnberger, A. (2012). Exploring Relationships between Recreation Specialization, Restorative Environments and Mountain Hikers' Flow Experience. Leisure Sciences, 34: $95-114$.

[47] Wu, C.H.J. \& Liang, R.D. (2011), The Relationship Between White-Water Rafting Experience Formation and Customer Reaction: A Flow Theory Perspective. Tourism Management, 32 (2): 317-325.

[48] Xun, J. (2010). Applying Netnography to Market Research: The Case of the Online Forum. Journal of Targeting, Measurement and Analysis for Marketing, 18 (1): 17-31.

[49] Yalcin, M., Kardesoglu, E. \& Isilak, Z. (2011). Yuksek İrtifa ve Kalp [High Altitude and Heart]. TAF Prev. Med. Bult, 10 (2): 211-222.

[50] Yang, J.K. (2015). The Relationship among Community Spirit, Community Identification, and Community Loyalty of Online Sports Community User. Crnogorska Sportska Akademija, Sport Mont, 1 (43-45): 75-82.

[51] Yaniklar, C. (2014). Sanal Topluluklar ve Geleneksel Topluluklar Arasindaki Farkliliklarin Sosyolojik Bir Analizi [A Sociological Analysis of Differences between Virtual Communities and Traditional Communities]. Sosyoloji Arastirmalari Dergisi [Journal of Sociology Research], 17(1): 159-190.

[52] Yao, C.Y., Tsai, C.C. \& Fang, Y.C. (2015). Understanding Social Capital, Team Learning, Members' E-Loyalty and Knowledge Sharing in Virtual Communities. Total Quality Management, 26 (6): 619-631.

[53] Kozinets, R.V. (1997). I want to believe: a netnography of the X-Philes' subculture of consumption", in Brucks, M. and MacInnis, D.J. (Eds). Advances in Consumer Research, 24, Association for Consumer Research, Provo, UT, 470-475.

[54] Hammersley, M. \& Atkinson, P. (1995), Ethography: Principles in Practice, 2nd ed., Routledge, New York, NY.

[55] Langer, R. \& Beckman, S. (2005). Sensitive research topics: netnography revisited. Qualitative Market Research, 8(2), 189-203. 